\title{
Assessing the Need for Diabetes Self-Management Education in the Oklahoma City Vietnamese Community
}

Teresa Truong · Mark Britton • Donald Harrison • Nancy Letassy • Becky Armor · Darryl Tonemah • Ann Nguyen

Received: November 1, 2010 / Published online: February 11, 2011

(c) The Author(s) 2011. This article is published with open access at Springerlink.com

\section{ABSTRACT}

Introduction: To assess the diabetes selfmanagement educational (DSME) needs of the Vietnamese diabetic population in the Oklahoma City metropolitan area. Methods: Participants in this explorative study included 50 Vietnamese adults with type 1 or type 2 diabetes recruited from the offices of four primary care physicians in the Oklahoma City metropolitan area. Participants completed a culturally sensitive survey focused on their diabetes history, knowledge and need of

Teresa Truong $(\varangle)$

Department of Pharmacy, Clinical and Administrative Sciences, University of Oklahoma College of Pharmacy, 1110 N. Stonewall Avenue, Oklahoma City, OK, USA.

Email: teresa-truong@ouhsc.edu

Mark Britton · Donald Harrison · Nancy Letassy •

Becky Armor · Ann Nguyen

Department of Pharmacy: Clinical and Administrative

Sciences, University of Oklahoma College of Pharmacy,

Oklahoma City, OK, USA

Darryl Tonemah

American Indian Health Management and Policy,

Oklahoma City, OK, USA
DSME, and health beliefs. Responses were evaluated using means and frequency analysis. Results: The mean age of participants was $62.7 \pm 9.1$ years. Over $80 \%$ of participants were most comfortable speaking and reading Vietnamese, and $62 \%$ had never received a high school diploma. Less than $50 \%$ of participants reported ever receiving education regarding diabetic complications, nutrition, desirable glycated hemoglobin values, diabetic medications, daily self-care, risk of smoking, or cardiovascular risk associated with diabetes. More than $80 \%$ of participants requested more education in all areas of DSME except smoking risk in diabetes, with all participants requesting delivery of this education in Vietnamese. Conclusion: DSME is needed and desired in the Vietnamese community of the Oklahoma City metropolitan area. Education should be provided in the Vietnamese language with most targeted to lower literacy levels. Vietnamese diabetes educators should facilitate increased access to DSME knowledge and skills in efforts to improve glycemic control and overall health status for this community.

Keywords: Asian; diabetes; diabetes selfmanagement education; Vietnamese 


\section{INTRODUCTION}

A national survey conducted by the National Diabetes Information Clearinghouse between 2004 and 2006 in people greater than 20 years of age indicated that $7.5 \%$ of Asian-Americans have been diagnosed with diabetes compared with $6.6 \%$ in non-Hispanic whites. ${ }^{1}$ Although diabetes prevalence is apparently higher among Asian-Americans, current data may be an underestimate. Diabetes risk in this group may be under recognized since Asian-Americans generally have bodies that are leaner than those usually expected of individuals with diabetes. Of note, some studies have reported that Asian patients have a significantly greater amount of visceral adipose tissue than Caucasian patients with the same waist circumference and body mass index (BMI). ${ }^{2-3}$ This finding is concerning since visceral adipose tissue has been linked to diabetes and cardiovascular disease. ${ }^{4}$ As a result of this data, the World Health Organization, the International Association for the Study of Obesity, and the International Obesity Task Force created a document proposing to redefine obesity in Asian-Americans and Pacific Islanders..$^{5-7}$ If approved and implemented, diabetes screening would likely occur more often among Asian-American patients, and diabetes prevalence may be found to be significantly higher than currently reported.

Given the higher prevalence of diabetes in Asian-Americans, it is important to evaluate what members of this population are doing to alter the course of their disease. Evidence shows that diabetes self-management education (DSME) can reduce diabetic complications and improve self-management, health status, and overall glycemic control. ${ }^{8-10}$ Previous studies have shown that DSME provided in Spanish for Hispanics and Latinos resulted in significant improvement in diabetes management. ${ }^{11,12}$
The Starr County border health initiative has produced several studies in support of culturally tailored DSME for Mexican Americans. One study in particular evaluated DSME using a culturally competent approach in terms of language, diet, social emphasis, family participation, and cultural health beliefs. This education resulted in significantly lower levels of glycated hemoglobin $\left(\mathrm{HbA}_{1 \mathrm{C}}\right)$ and fasting blood glucose at 6 and 12 months and higher diabetes knowledge scores compared with usual care from private physicians or local clinics. ${ }^{11}$ Another study described the success of a community-based DSME program for Latinos with low income and low rate of medical insurance. ${ }^{12}$ The positive outcomes of many Hispanic and Latino DSME programs demonstrate the potential success for culturally tailored diabetes education in the AsianAmerican population since they share many similar characteristics. However, the extent to which Asian-Americans receive this important education is currently unknown.

The term "Asian-American" encompasses various subpopulations with origins from multiple Asian countries that share similar beliefs. Throughout the rest of this article, the Vietnamese population specifically will be discussed.

Language is one barrier that must be considered when evaluating the extent of diabetes education received by Vietnamese patients. In 2002, Halsted et al. conducted an outreach project specifically for the Vietnamese community of Houston, providing them with consumer health information. ${ }^{13}$ While gathering background information for this project, these investigators found that $90 \%$ of this community was composed of immigrants, with a majority of them reaching adulthood in their native land. They also discovered that most of these patients obtained medical 
and health information through ethnic radio programming, ethnic newspapers, and community-based organizations that primarily used the Vietnamese language. Findings from this study suggest that language may be a significant barrier for these patients to overcome in American society. ${ }^{13}$ Additionally, in the California Endowment report, $42 \%$ of Vietnamese people reported that they were not able to fully understand their health problems because explanations were not provided in their native language. ${ }^{14}$ Although these studies were performed in other cities, their findings may be pertinent to the Oklahoma City Vietnamese community since many of them appear to share the same characteristics of being immigrants, living in defined areas with cultural distinction, and holding to traditional values.

According to United States Census Bureau data from 2006, Oklahoma was ranked 30th in the nation for the percentage of AsianAmericans. ${ }^{15}$ The Oklahoma Asian-American population totaled 57,788 with 15,468 (27\%) of them being Vietnamese, making this group the largest Asian subpopulation in the state. ${ }^{16}$ Oklahoma City is the most populous city and home to the greatest number of Asian-Americans in the state. Between 2005 and 2009, Oklahoma City had an estimated 546,031 inhabitants with 21,615 (3.9\%) of them being Asian-American; of this group, 9891 were of Vietnamese origin, representing $45.8 \%$ of the city's entire AsianAmerican population. ${ }^{17,18}$

Very little is known about the Vietnamese diabetic population of Oklahoma according to the outreach coordinator from the Harold Hamm Oklahoma Diabetes Center and the coordinator of the Diabetes Prevention and Control Program from the Oklahoma State Department of Health. Specifically, data regarding adequacy and need of DSME for these patients has not been published. The hypothesis of this study is that Vietnamese patients with diabetes need DSME; therefore, the primary objective of this study was to assess the DSME needs of the Vietnamese diabetic population of Oklahoma City. The secondary objective was to determine preferred ways to educate this population.

\section{METHODS}

This explorative study, approved by the University of Oklahoma Health Sciences Center Institutional Review Board, gathered pertinent data from patients through the use of a survey developed to reflect content from the National Standards for DSME. ${ }^{19}$ Surveys were made available between December 2008 and April 2010 in the offices of four physicians serving the majority of residents of the Vietnamese community in the Oklahoma City metropolitan area.

\section{Participants}

Vietnamese patients $\geq 18$ years of age and having a diagnosis of either type 1 or type 2 diabetes were eligible for this study. Those who did not meet the inclusion criteria were excluded. Informed consent was given by participants when they chose to complete and hand in the survey.

\section{Study Procedure and Data Collection}

Participants were identified in the offices of four primary care physicians located in the Oklahoma City metropolitan area. These participating physicians were identified via Vietnamese community church leaders and members of the Asian Health Coalition, and are believed to serve the majority of the Vietnamese diabetic population. Physicians 
were given information regarding the purpose of the study and the roles of their office staff in the research; physicians agreeing to participate signed an agreement letter confirming this willingness. A physician's signature also represented agreement from their office personnel. Eligible patients were identified by the physician and office personnel with the suggestion of using demographic data (age and ethnicity) and medical data (International Classification of Diseases, ninth edition [ICD9] codes in the 250.00 series indicating the presence of diabetes) found in the electronic billing systems of each individual practice. This method was suggested to maximize the identification of all potentially eligible patients while minimizing the burden on physicians and office personnel. Deidentified surveys, available in both English and Vietnamese to overcome any potential language barrier, were placed in the medical charts of all eligible patients for completion at follow-up visits. The survey contained three areas of focus as follows: (1) patient demographics and diabetes history, (2) previous and desired diabetes DSME, and (3) patient beliefs. With the assistance of each physician's office personnel, the survey was administered at each patient's next office visit. Completed surveys were stored in a secure location by office personnel until collected by researchers one to three times per month. The survey used was created specifically for this study by the lead author who is also fluent in Vietnamese. A search was performed for a validated instrument to assess DSME, however, no validated instruments were found. A survey that is used within the Indian Health System was identified; however, it did not gather information regarding patient beliefs and cultural influences. Therefore, we created a survey that included areas of diabetes history, diabetes education, and cultural assessment.

\section{Data Analysis}

Responses to survey items were entered into a Microsoft Office Excel (Microsoft Corporation, Redmond, WA, USA) database for analysis. Because of the exploratory nature of this research, the data analyses were mostly descriptive using frequency analysis and means to describe the results obtained.

\section{RESULTS}

\section{Characteristics of Respondents}

Approximately 200 surveys were placed in eligible patient charts several days prior to scheduled visit. A total of 74 patients were given surveys at their physicians' offices with 50 choosing to complete it for a $68 \%$ response rate; the remaining 24 chose not to participate. Surveys were not given when patients were not seen in clinic during the study period. Data from all 50 of these participants met the inclusion criteria and were eligible for analysis. Respondents ranged in age from 43 to 89 years, with a mean of $62.7 \pm 9.1$ years, and they were relatively equally distributed between the genders with 26 (52\%) identifying themselves as female, 23 (46\%) identifying as male, and one failing to indicate gender. Additionally, the majority of respondents, 38 (76\%), were married, with five (10\%) being widowed, three (6\%) being single, three (6\%) being divorced, and one not indicating marital status. Other characteristics of the study participants pertinent to assessing their needs for DSME are outlined in Table 1. Of note, most respondents $(62 \%)$ had not completed 12th grade, and the vast majority indicated being most comfortable speaking (86\%) and reading (84\%) the Vietnamese language. In fact, all respondents chose to complete the Vietnamese rather than the English version of the survey. 
Table 1. Characteristics of respondents.

\begin{tabular}{|c|c|}
\hline Characteristic & $\begin{array}{c}\text { No. of responses } \\
\text { (\% of respondents), } \\
n=50\end{array}$ \\
\hline \multicolumn{2}{|l|}{ Highest level of education attained: } \\
\hline Kindergarten through fifth grade & $8(16)$ \\
\hline Sixth to eighth grade & $12(24)$ \\
\hline Ninth to 11 th grade & $11(22)$ \\
\hline High school, GED, or vo-tech & $11(22)$ \\
\hline Some college & $4(8)$ \\
\hline Bachelors degree & $1(2)$ \\
\hline Masters degree & 0 \\
\hline Doctoral degree & 0 \\
\hline No response & $3(6)$ \\
\hline \multicolumn{2}{|l|}{ Language most comfortable speaking: } \\
\hline Vietnamese & $43(86)$ \\
\hline Both Vietnamese and English & $4(8)$ \\
\hline English & $1(2)$ \\
\hline No response & $2(4)$ \\
\hline \multicolumn{2}{|l|}{ Language most comfortable reading: } \\
\hline Vietnamese & $42(84)$ \\
\hline Both Vietnamese and English & $4(8)$ \\
\hline English & $1(2)$ \\
\hline No response & $3(6)$ \\
\hline \multicolumn{2}{|l|}{ Insurance: } \\
\hline No insurance & $23(46)$ \\
\hline Medicare only & $7(14)$ \\
\hline Private insurance & $6(12)$ \\
\hline Both Medicare and Medicaid & $5(10)$ \\
\hline Medicaid only & $1(2)$ \\
\hline Other & $1(2)$ \\
\hline No response & $7(14)$ \\
\hline \multicolumn{2}{|l|}{ Pertinent medical history: } \\
\hline Hypertension & $34(68)$ \\
\hline Dyslipidemia & $34(68)$ \\
\hline Previous myocardial infarction & $4(8)$ \\
\hline Previous stroke & $1(2)$ \\
\hline \multicolumn{2}{|l|}{ Smoking status: } \\
\hline Never smoked & $34(68)$ \\
\hline Previous smoker & $13(26)$ \\
\hline Current smoker & $2(4)$ \\
\hline No response & $1(2)$ \\
\hline
\end{tabular}

GED=General Equivalency Diploma; vo-tech=vocationaltechnical degree.
Most participants (46\%) were uninsured with only $26 \%$ being covered by Medicaid, Medicare, or both. A small number (12\%) had private health insurance. In all, $68 \%$ of patients had hypertension and dyslipidemia, significant risk factors for developing complications from their diabetes. Most (68\%) had never smoked, and 26\% indicated quitting an average of 15 years prior to completing the survey. Only $4 \%$ indicated that they were actively smoking at the time of the survey.

\section{Diabetes History, Treatment, and Complications}

The average known duration of diabetes was reported by respondents to be $6.7 \pm 5.4$ years, with responses ranging widely from 2 months to 30 years. Additional details of respondents' diabetes history, treatments, and complications are included in Table 2 . Notably, while $26 \%$ of respondents reported having type 2 diabetes and only $2 \%$ reported having type 1 diabetes, most (66\%) were unaware of the classification of their diabetes. Most participants (82\%) reported using oral medications to treat their diabetes, and only $8 \%$ indicated the use of insulin. No patients reported a hospitalization because of hyperglycemia, and none had suffered from an amputation as a complication of diabetes. However, five individuals (10\%) reported a hospital visit because of hypoglycemia. The extent of other complications from diabetes is unclear from the survey responses; however, six $(12 \%)$ reported visual problems, two (4\%) reported kidney problems, and nine (18\%) reported loss of feelings in their hands or feet. Obviously, further medical evaluation is necessary to determine if these self-reported problems actually indicate the presence of retinopathy, nephropathy, and neuropathy as a complication of diabetes. 
Table 2. Responses to questions about diabetes treatment and complications.

\begin{tabular}{|c|c|}
\hline Questions and responses & $\begin{array}{c}\text { No. of responses } \\
\text { (\% of respondents), } \\
n=50\end{array}$ \\
\hline \multicolumn{2}{|c|}{ What type of diabetes do you have? } \\
\hline Type 1 diabetes & $1(2)$ \\
\hline Type 2 diabetes & $13(26)$ \\
\hline Not sure & $33(66)$ \\
\hline No response & $3(6)$ \\
\hline \multicolumn{2}{|c|}{ What treatments are you using for diabetes? } \\
\hline Prescription oral agent(s) & $41(82)$ \\
\hline Prescription insulin(s) & $4(8)$ \\
\hline Special diet & $12(24)$ \\
\hline Herbal medication $(s)$ & $2(4)$ \\
\hline None & $1(2)$ \\
\hline Don't know or not sure & $5(10)$ \\
\hline No response & $2(4)$ \\
\hline \multicolumn{2}{|c|}{$\begin{array}{l}\text { Have you ever been taken to the hospital because your } \\
\text { blood sugar was too high? }\end{array}$} \\
\hline Yes & 0 \\
\hline No & $49(98)$ \\
\hline Don't know & 0 \\
\hline No response & $1(2)$ \\
\hline \multicolumn{2}{|c|}{$\begin{array}{l}\text { Have you ever been taken to the hospital because you } \\
\text { blood sugar was too low? }\end{array}$} \\
\hline Yes & $5(10)$ \\
\hline No & $43(86)$ \\
\hline Don't know & $1(2)$ \\
\hline No response & $1(2)$ \\
\hline \multicolumn{2}{|c|}{ Do you have vision problems because of diabetes? } \\
\hline Yes & $6(12)$ \\
\hline No & $35(70)$ \\
\hline Don't know & $6(12)$ \\
\hline No response & $3(6)$ \\
\hline \multicolumn{2}{|c|}{ Do you have kidney problems because of diabetes? } \\
\hline Yes & $2(4)$ \\
\hline No & $41(82)$ \\
\hline Don't know & $6(12)$ \\
\hline No response & $1(2)$ \\
\hline \multicolumn{2}{|c|}{$\begin{array}{l}\text { Do you have loss of feeling in hands or feet because of } \\
\text { diabetes? }\end{array}$} \\
\hline Yes & $9(18)$ \\
\hline No & $33(66)$ \\
\hline Don't know & $6(12)$ \\
\hline No response & $2(4)$ \\
\hline \multicolumn{2}{|c|}{ Have you lost limbs due to diabetes? } \\
\hline Yes & 0 \\
\hline No & $49(98)$ \\
\hline Don't know & 0 \\
\hline No response & $1(2)$ \\
\hline
\end{tabular}

\section{Diabetes Education Received and Desired}

Table 3 summarizes responses of respondents to questions assessing their knowledge about diabetes and self-care skills as well as their desire for additional DSME. Only half the respondents indicated receiving any diabetes education, and only $62 \%$ indicated knowing what diabetes was. A total of $44 \%$ of respondents received education about diabetic complications, but only 38\% reported knowing the long-term complications and $32 \%$, the short-term complications. A total of $46 \%$ of participants reported receiving information on nutrition, and 56\% knew which types of foods affected blood sugar. Regarding physical activity, 58\% received some education about the effects of exercise on blood sugar; however, only 36\% knew what type of exercises are recommended. Participants seemed to be somewhat knowledgeable about home blood glucose monitoring with 64\% receiving education about this important aspect of self-management. In all, $60 \%$ possessed a glucometer and 50\% reported knowledge of how often to check blood glucose at home. In contrast, participants did not seem familiar with goals of therapy. Only $4 \%$ reported receiving education about hemoglobin $\mathrm{HbA}_{1 \mathrm{C}}$ values, $14 \%$ reported knowing what their target $\mathrm{HbA}_{1 \mathrm{C}}$ should be, and 28\% indicated knowing target levels for glucose readings at home. Although most participants were on prescribed diabetes medications, only 34\% received education about their medications, only $24 \%$ knew how their medications worked, and only $16 \%$ were familiar with side effects of their diabetes medications. Although relatively low percentages of participants indicated receiving education about key areas of DSME, $80 \%$ or more of all patents expressed a desire for more information about all topics except the risk of smoking and smoking cessation. 
Table 3. Responses to questions about diabetes education received and desired.

No. of responses for each category

Educational categories (\% of respondents), $n=50$

Overview of diabetes:
Have you received education about diabetes?
Do you know what diabetes is?
Would you like information on how diabetes affects the body?
Diabetic complications:
Have you ever received education about diabetic complications?
Do you know what the long-term complications of diabetes are?
Do you know what the short-term complications of diabetes are?
Do you think the complications of diabetes can be prevented?
Would you like information about diabetic complications?

Nutrition:

Have you ever received education about foods that can affect blood sugars?

Do you know how types of food affect the blood sugar?

Would you like information about a proper diet?

Exercise:

Have you received education about the effects of exercise on blood sugars?

Do you know which exercises are recommended for patients with diabetes?

Would you like information on exercise for treatment of diabetes?

Home glucose monitoring:

Have you ever received education about checking your blood sugars at home?

Do you have a blood sugar machine?

Do you know how often to check your blood sugars at home?

Would you like information on checking your sugar and blood sugar machines?

Hemoglobin $\mathrm{HbA}_{1 \mathrm{C}}$ :

Have you ever received education about what the $\mathrm{HbA}_{1 \mathrm{C}}$ is?

Do you know what level your HbA1C should be?

Do you know what level your home blood sugar readings should be?

Would you like more information on desired blood sugar levels?

Medications for diabetes:

Have you ever received education about your diabetic medications?

Do you know how your diabetic medications work?

Do you know the side effects to your diabetic medications?

Would you like information on diabetic medications?

Daily self-care:

Have you ever received education about daily self-care?

Do you check your feet every day?

Do you put lotion on your feet every day?

Would you like information on daily self-care?

Smoking:

Have you ever received information about smoking with diabetes?

Have you ever received education on smoking cessation?

Would you like information on the effects of smoking with diabetes?

Would you like information on smoking cessation?

Heart disease:

Have you ever received education about the risk of heart disease and diabetes?

Would you like information about the impact of diabetes on heart disease?

\begin{tabular}{cccc}
\multicolumn{4}{c}{ (\% of respondents), $n=50$} \\
Yes & No & Don't & No \\
& know & response
\end{tabular}

\begin{tabular}{|c|c|c|c|}
\hline $25(50)$ & $20(40)$ & $4(8)$ & $1(2)$ \\
\hline $31(62)$ & $17(34)$ & 0 & $2(4)$ \\
\hline $42(84)$ & $5(10)$ & 0 & $3(6)$ \\
\hline $22(44)$ & $24(48)$ & $2(4)$ & $2(4)$ \\
\hline $19(38)$ & $28(56)$ & 0 & $3(6)$ \\
\hline $16(32)$ & $30(60)$ & 0 & $4(8)$ \\
\hline $33(66)$ & $14(28)$ & 0 & $3(6)$ \\
\hline $48(96)$ & $1(2)$ & 0 & $1(2)$ \\
\hline $23(46)$ & $23(46)$ & $2(4)$ & 0 \\
\hline $28(56)$ & $22(44)$ & 0 & 0 \\
\hline $48(96)$ & $1(2)$ & 0 & $1(2)$ \\
\hline $29(58)$ & $18(36)$ & $2(4)$ & $1(2)$ \\
\hline $18(36)$ & $32(64)$ & 0 & 0 \\
\hline $46(92)$ & $3(6)$ & 0 & $1(2)$ \\
\hline $32(64)$ & $17(34)$ & 0 & $1(2)$ \\
\hline $30(60)$ & $20(40)$ & 0 & 0 \\
\hline $25(50)$ & $24(48)$ & 0 & $1(2)$ \\
\hline $40(80)$ & $8(16)$ & 0 & $2(4)$ \\
\hline $2(4)$ & $42(84)$ & $4(8)$ & $2(4)$ \\
\hline $7(14)$ & $40(80)$ & 0 & $3(6)$ \\
\hline $14(28)$ & $32(64)$ & 0 & $4(8)$ \\
\hline $44(88)$ & $4(8)$ & 0 & $2(4)$ \\
\hline $17(34)$ & $30(60)$ & $2(4)$ & $1(2)$ \\
\hline $12(24)$ & $35(70)$ & 0 & $3(6)$ \\
\hline $8(16)$ & $40(80)$ & 0 & $2(4)$ \\
\hline $43(86)$ & $5(10)$ & 0 & $2(4)$ \\
\hline $16(32)$ & $31(62)$ & $1(2)$ & $2(4)$ \\
\hline $20(40)$ & $30(60)$ & 0 & 0 \\
\hline $14(28)$ & $34(68)$ & 0 & $2(4)$ \\
\hline $47(94)$ & $2(4)$ & 0 & $1(2)$ \\
\hline $11(22)$ & $36(72)$ & $1(2)$ & $2(4)$ \\
\hline $13(26)$ & $33(66)$ & $1(2)$ & $3(6)$ \\
\hline $16(32)$ & $30(60)$ & 0 & $4(8)$ \\
\hline $17(34)$ & $29(58)$ & 0 & $4(8)$ \\
\hline $19(38)$ & $30(60)$ & $1(2)$ & 0 \\
\hline $44(88)$ & $6(12)$ & 0 & 0 \\
\hline
\end{tabular}

$\mathrm{HbA}_{1 \mathrm{C}}=$ glycated hemoglobin. 
When questioned about preferred sources and methods of education, $60 \%$ of respondents expressed wanting to receive education from a healthcare provider, with 34\% desiring it from a newspaper and 34\% from their church. Health fairs (22\%), family or friends (22\%), radio (14\%), television (14\%), computers (10\%), small groups $(10 \%)$, pamphlets $(6 \%)$, temple $(6 \%)$, and telephone $(2 \%)$ were other sources cited by study participants. Not surprisingly, $86 \%$ of survey respondents preferred to receive diabetes education in the Vietnamese language with $12 \%$ stating a preference for both English and Vietnamese.

\section{Patient Beliefs}

Table 4 summarizes respondents' beliefs about their diabetes. Most (66\%) believed they have

Table 4. Responses to questions about patient beliefs.

\begin{tabular}{lc}
\hline Questions and responses & $\begin{array}{c}\text { No. of responses } \\
\text { \% of respondents), } \\
n=50\end{array}$ \\
\hline How do you believe you got diabetes? & \\
Diet & $33(66)$ \\
Family history & $13(26)$ \\
Other & $4(8)$ \\
Daily habits & $3(6)$ \\
Medications & 0 \\
No response & $2(4)$ \\
Do you believe diabetes is preventable? & \\
Yes & $37(74)$ \\
No & $3(6)$ \\
Don't know & $10(20)$ \\
Do you believe diabetes is controllable? & \\
Yes & $40(80)$ \\
No & $2(4)$ \\
Don't know & $7(14)$ \\
No response & $1(2)$ \\
How important is controlling diabetes to you? \\
Very important & $26(52)$ \\
Important & $24(48)$ \\
Moderately important & 0 \\
Of little importance & 0 \\
Unimportant & 0 \\
\hline
\end{tabular}

diabetes because of their diet, while others believed their diabetes is due to a family history (26\%), daily habits (6\%), or other unspecified causes $(8 \%)$. A total of $74 \%$ believed that diabetes is preventable, $80 \%$ believed it is controllable, and $100 \%$ of participants believed that it is either very important or important to control diabetes.

\section{DISCUSSION}

There are few studies evaluating the need for DSME specifically for the Vietnamese population. As hypothesized, results of this study in Oklahoma City suggest that the Vietnamese respondents have not received adequate DSME, and the findings also raise issues for further study and consideration by those interested in serving this unique population. Language is likely a significant issue in the design and delivery of effective DSME for the Vietnamese population of Oklahoma City. All respondents chose to complete the Vietnamese version of the survey, and the vast majority expressed feeling most comfortable reading and speaking the Vietnamese language. Additionally, most of the survey respondents indicated that they had not completed 12th grade. Given the ages of most respondents, it is likely that most of this education may have been delivered in Vietnam; however, the survey instrument did not allow for verification of this speculation. These findings are comparable to those reported by the Asian Nation Organization. ${ }^{20}$ Obviously efforts to impact glycemic control and reduce the risk of complications in many Vietnamese patients with diabetes must be supported by written materials in the Vietnamese language and at the literacy level of those using them.

Many patients in this small study had not received DSME, but the majority were interested in receiving it from a healthcare 
provider. Unfortunately, the survey did not allow respondents to indicate what type of healthcare provider would be acceptable. Clearly, diabetes educators familiar with the Vietnamese language and culture could be helpful in meeting these patients' needs. Beyond DSME oriented to individual patients, education may also be targeted to family members more proficient with the English language. This method would appreciate the strong familial relationships between members of Vietnamese families in the United States and may be another way to overcome a potential language barrier towards effective DSME in Vietnamese patients. ${ }^{21}$ Finally, regardless of who provides DSME, patient access to these needed services may be affected by the financial circumstances of patients since $46 \%$ of survey respondents indicated having no insurance and less than half, only 38\%, indicated having any type of health insurance, either private or government supported via Medicare or Medicaid programs.

Three other findings of this survey may be of interest to healthcare providers caring for Vietnamese patients with diabetes. First, these patients may be at significant risk for microvascular and macrovascular complications because in addition to diabetes, $68 \%$ of respondents also had diagnoses of hypertension and dyslipidemia. Second, even though smoking is a social norm in Vietnamese culture with one study reporting that over $70 \%$ of men in Vietnam are smokers, ${ }^{22}$ our survey found very few active smokers, and relatively few patients, about onethird, were interested in learning about smoking cessation or the effects of smoking on their diabetes. Finally, it is noteworthy that $66 \%$ of survey respondents believed that their diabetes is a result of their diet. Our study was not designed to determine if this belief is related to knowledge of the balance of carbohydrates in the diet or to traditional beliefs held by some Vietnamese Americans. Specifically, many Vietnamese immigrants among other Asian groups in the United States believe that illnesses and diseases are caused by the imbalance of "yin" and "yang" or the imbalance of "hot" and "cold" elements inside their body. ${ }^{22,}{ }^{23}$ It is believed that these elements are dependent on the foods ingested. ${ }^{23}$ Therefore, the nutritional component of DSME provided to Vietnamese must appreciate this belief system and may be more challenging for diabetes educators and other healthcare providers.

Limitations of this study include smaller sample size, the use of self-reported measures, and the simplicity of the survey instrument itself. Reliance on the office staff of participating physicians to distribute the survey to the targeted population may have contributed to a smaller number of respondents, especially if these patients were being seen during particularly busy periods. Additionally, some patients may have declined participation, choosing not to complete discretionary paperwork in the face of the many required forms common in healthcare today. Self-reporting is often used in survey studies to gather foundational information; however, the accuracy and thoroughness of answers to survey items depend on the patients' motivation, memory, and ability to interpret questions and respond appropriately. In addition, some respondents may have provided answers to place themselves in a more favorable light even though they were informed that the results were entirely anonymous. ${ }^{24}$ Finally, the simplicity of the survey instrument itself did not allow for full interpretation of the responses provided; for example, a positive response to a question such as "Do you have vision problems because of diabetes?" does not provide sufficient information to interpret causation or even relationship to diabetes. In addition, the reliability and 
validity of the survey instrument was not tested. However, the survey items were intended simply to gain initial information and provide guidance for studies of greater intensity and rigor. Given all of these limitations, it is difficult to generalize these study results and suggested actions.

\section{CONCLUSIONS}

DSME is needed and desired within the Vietnamese community of Oklahoma City. Development and evaluation of the effectiveness of culturally sensitive materials and educational approaches may be beneficial to Vietnamese patients with diabetes. Further studies are needed to strengthen our findings.

\section{ACKNOWLEDGMENTS}

The authors would like to thank Dr. Boyd Shook, Dr. Quang Pham, Dr. Liem Trang, and Dr. Thuy Nguyen along with all of their office staff and volunteers for their assistance and dedication throughout this study. Additionally, the authors thank Kaitlyn Cao for her assistance in data collection. The authors declare that they have no conflict of interest. TT is the guarantor for this article, and takes responsibility for the integrity of the work as a whole.

Open Access. This article is distributed under the terms of the Creative Commons Attribution Noncommercial License which permits any noncommercial use, distribution, and reproduction in any medium, provided the original author(s) and source are credited.

\section{REFERENCES}

1. National Diabetes Information Clearinghouse. Race and Ethnic Differences in Prevalence of Diagnosed Diabetes. Available at: http://diabetes.niddk.nih.gov/ dm/pubs/statistics/. Accessed November 24, 2008.
2. Kadowaki T, Sekikawa A, Murata K, et al. Japanese men have larger areas of visceral adipose tissue than Caucasian men in the same levels of waist circumference in a population-based study. Int J Obes. 2006;30:1163-1165.

3. Lear SA, Humphries KH, Kohli S, Birmingham CL. The use of BMI and waist circumference as surrogates of body fat differs by ethnicity. Obesity. 2007;15:2817-2824.

4. Rosito GA, Massaro JM, Hoffmann U, et al. Pericardial fat, visceral abdominal fat, cardiovascular disease risk factors, and vascular calcification in a community-based sample; The Framingham Heart Study. Circulation. 2008;117:605-613.

5. World Health Organization. BMI Classification. Available at: www.who.int/bmi/index.jsp?introPage =intro_3.html. Accessed January 7, 2009.

6. World Health Organization Western Pacific Region. The Asia-Pacific Perspective-Redefining Obesity Report, February 2000. Available at: www.wpro.who. int/NR/rdonlyres/0A35147B-B1D5-45A6-9FF2F7D86608A4DE/0/Redefiningobesity.pdf. Accessed January 7, 2009.

7. National Diabetes Education Program. Silent Trauma: Diabetes, Health Status, and the Refugee. Southeast Asians in the United States. Available at: www.ndep.nih.gov/diabetes/pubs/SilentTrauma. pdf. Accessed November 24, 2008.

8. Brown SA, Hanis CL. Culturally competent diabetes education for Mexican Americans: the Starr County study. Diabetes Educ. 1999;25:226-236.

9. Clement S. Diabetes self-management education. Diabetes Care. 1995;18:1204-1214.

10. Williams GC, Zeldman A. Patient-centered diabetes self-management education. Curr Diab Rep. 2002;2:145-152.

11. Brown SA. Garcia AA. Kouzekanani K. Hanis CL. Culturally competent diabetes self-management education for Mexican Americans: the Starr County border health initiative. Diabetes Care. 2002;25:259-268.

12. Lorig K, Gonzalez VM. Community-based diabetes self-management education: definition and case study. Diabetes Spectrum. 2000;13:234.

13. Halsted DD, Varman B, Sullivan M, Nguyen L. Consumer health information for Asians (CHIA): a collaborative project. J Med Libr Assoc. 2002;90:400-405. 
14. New California Media (NCM). Bridging Language Barriers in Health Care: Public Opinion Survey of California Immigrants from Latin America, Asia and the Middle East: The California Endowment; 2003.

15. U.S. Census Bureau. The 2010 Statistical Abstract: State Ranking. Available at www.census.gov/ compendia/statab/rankings.html. Accessed January 7, 2009.

16. U.S. Census Bureau. Oklahoma: American Community Survey Demographic and Housing Estimates: 2005-2009. Available at: http://factfinder. census.gov/servlet/ADPTable?_bm=y\&-geo_id= 04000US40\&-qr_name=ACS_2009_5YR_G00_ DP5YR5\&-ds_name=ACS_2009_5YR_G00_\&-_lang $=$ en $\&$-redoLog=false\&-_sse=on. Accessed January 26, 2011.

17. U.S. Census Bureau. Oklahoma City, Oklahoma: American Community Survey Demographic and Housing Estimates: 2005-2009. Available at: http://factfinder.census.gov/servlet/ADPTable? bm=y\&-geo_id=16000US4055000\&-qr_name=ACS_ 2009_5YR_G00_DP5YR5\&-ds_name=ACS_2009_ 5YR_G00_\&-_lang=en\&-_sse=on. Accessed January 26, 2011.
18. The Associated Press. Oklahoma's Asian population thrives, census shows. The Oklahoman. Available at: http://newsok.com/article/3280111/?print=1. Accessed January 7, 2009.

19. Funnell MM, Brown TL, Childs BP, et al. National standards for diabetes self-management education. Diabetes Care. 2007;30:1630-1637.

20. Asian Nation. Asian American history, demographics, and issues. Available at: www.asian-nation.org/ demographics.shtml. Accessed June 10, 2009.

21. Nguyen D. Culture shock--a review of Vietnamese culture and its concepts of health and disease. West J Med. 1985;142:409-412.

22. Jenkins CN, Dai PX, Ngoc DH, et al. Tobacco use in Vietnam. Prevalence, predictors, and the role of the transnational tobacco corporations. JAMA. 1997;277:1726-1731.

23. Ngo-Metzger Q, Massagli MP, Clarridge BR, et al. Linguistic and cultural barriers to care. J Gen Intern Med. 2003;18:44-52.

24. Fowler FJ. Survey Research Methods. 4th edition. Los Angeles, CA: Sage Publications; 2009. 